\title{
Phytochemical screening and toxicity testing of Atuna racemosa Rafin. chrysobalanaceae shell and seed extracts
}

\author{
Jinebeth M. Pacaňa ${ }^{1}$, Van Ryan Kristopher R. Galarpe ${ }^{2, *}$ \\ ${ }^{1}$ Chemistry Department (BS Chemistry), University of Science and Technology of Southern Philippines (formerly Mindanao University of Science \\ and Technology), Cagayan de Oro, Philippines \\ ${ }^{2}$ Physics Department, University of Science and Technology of Southern Philippines (formerly Mindanao University of Science and Technology), \\ Cagayan de Oro, Philippines
}

\section{ART ICLE IN F O}

\section{Article history:}

Received 2 February 2017

Received in revised form

8 September 2017

Accepted 11 September 2017

\section{Keywords:}

Atuna racemosa

Phytochemical

Lethality assay

Extracts

\begin{abstract}
A B S T R A C T
This research evaluated the phytochemical profile and toxicological properties of the aqueous, ethyl acetate, methanol, and decocted extracts of the shell and seed of Atuna racemosa Rafin. Chrysobalanaceae (tabon-tabon). The phytochemical screening was qualitatively tested while Brine Shrimp Lethality Assay (BSLA) was employed for toxicity testing of the extracts. Phytochemical screening of $A$. racemosa extracts resulted in the detection of the presence of alkaloids, anthraquinones, coumarins, flavonoids, saponins, tannins and terpenoids. The $A$. racemosa shell and seed extracts induced medium to highly toxic activity to brine shrimp nauplii at $\mathrm{LC}_{50}$ values of $268.605 \mu \mathrm{g} / \mathrm{mL}$ (aqueous shell) $165.195 \mu \mathrm{g} / \mathrm{mL}$ (aqueous seed), 277.9 $\mu \mathrm{g} / \mathrm{mL}$ (ethyl acetate shell), $419.919 \mu \mathrm{g} / \mathrm{mL}$ (ethyl acetate seed), 116.032 $\mu \mathrm{g} / \mathrm{mL}$ (methanol shell), $92.0427 \mu \mathrm{g} / \mathrm{mL}$ (methanol seed), $482.78 \mu \mathrm{g} / \mathrm{mL}$ (decoction shell), and $121.111 \mu \mathrm{g} / \mathrm{mL}$ (decoction seed), respectively. Ethyl acetate and methanol extracts of A. racemosa seed showed good toxicological properties. Further investigation is needed to determine the bioactive components present in these extracts.
\end{abstract}

(C) 2017 The Authors. Published by IASE. This is an open access article under the CC BY-NC-ND license (http://creativecommons.org/licenses/by-nc-nd/4.0/).

\section{Introduction}

Medicinal plants have continued to attract attention in the global search for effective antimicrobial agents because of its cheapness, availability, accessibility and the current problems associated with the use of antibiotics. Such problems are the microbial infections that lead to the production of highly reactive molecules from the metabolism of oxygen that can cause extensive damage to cells and tissues (Dhalwal et al., 2007).

The Atuna racemosa Rafin. Chrysobalanaceae, locally known as "tabon-tabon", is a little known and exotic tropical fruit that can be found in Northern Mindanao in the Philippines. The tree of the fruit also grows in Papua, New Guinea, Indonesia, Malaysia, Thailand and other tropical Asian countries and Pacific Islands. In Northern Mindanao, tabon-tabon extract is mainly used as a main ingredient of a rawfish dish however; no ethnobotanical studies have been conducted. Although few studies elsewhere of

\section{* Corresponding Author.}

Email Address: vanryangalarpe@gmail.com (V. R. K. R. Galarpe) https://doi.org/10.21833/ijaas.2017.011.017

2313-626X/@ 2017 The Authors. Published by IASE.

This is an open access article under the CC BY-NC-ND license

(http://creativecommons.org/licenses/by-nc-nd/4.0/)
A. racemosa (Buenz, 2006; 2007; Buenz et al., 2007) had been conducted, however, limited studies has been made involving comparison between shell and the seed of the fruit. Thus, investigating its phytochemical profile in several extracts and toxicity testing as initial study can be important for future product development. This study tries to understand the properties of the shell and seed of A. racemosa.

\section{Materials and method}

\subsection{Sample preparation}

The fruit samples were washed thoroughly with running water, cut lengthwise into quarters, and the seeds were scraped. The shell and seed were washed thoroughly, cut into pieces and dried at room temperature for five days with proper air ventilation. It was ground to fine powder using a laboratory scale mill or blender. Fig. 1 shows the sample use in this study.

\subsection{Preparation of extracts}

This procedure is as follows: 
- Decocted Extracts: In a one liter beaker, 50 grams of sample was placed and added with $800 \mathrm{~mL}$ distilled water. The mixture was bought to boiling for 30 minutes. The decocted extract was filtered and stored in the refrigerator at $4^{\circ} \mathrm{C}$ until use.

-Aqueous Extracts: A one is to five (1:5) ratio of the weight of the sample to the volume of the extracting solvent was used in the extraction. About 100 grams $A$. racemosa shell/seed were soaked in $500 \mathrm{~mL}$ distilled water at room temperature for 48 hours. The $A$. racemosa shell and seed aqueous extracts were filtered and concentrated in rotary evaporator at $95^{\circ} \mathrm{C}$. Then, it was stored in the refrigerator at $4^{\circ} \mathrm{C}$ until use.

-Ethyl acetate Extracts: About 100 grams A. racemosa shell/seed were soaked in $500 \mathrm{~mL}$ ethyl acetate at room temperature for 48 hours. The $A$. racemosa shell/seed ethyl acetate extracts were filtered and concentrated in rotary evaporator at $70^{\circ} \mathrm{C}$. Then, it was stored in the refrigerator at $4^{\circ} \mathrm{C}$ until use.

- Methanolic Extracts: About 100 grams A. racemosa shell/seed were soaked in $500 \mathrm{~mL}$ methanol at room temperature for 48 hours. The $A$. racemosa shell/seed methanolic extracts were filtered and concentrated in rotary evaporator at $55^{\circ} \mathrm{C}$. Then, it was stored in the refrigerator at $4^{\circ} \mathrm{C}$ until use. Figs. 2,3 , and 4 presents the schematic diagram of the study.

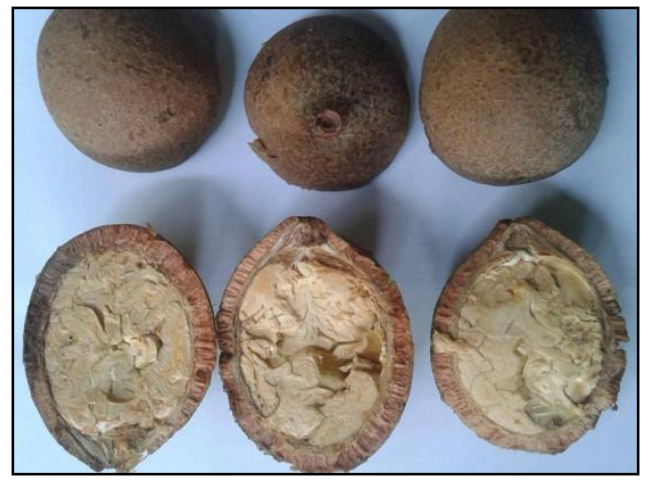

Fig. 1: A. racemosa Rafin. Chrysobalanaceae sample tested for the presence of phytochemicals and its toxicological effects

\subsection{Phytochemical screening for secondary plant metabolites}

This procedure is as follows:

- Screening for Alkaloids (Wagner's Test): A $5 \mathrm{~mL}$ of extract was stirred with $5 \mathrm{~mL}$ of $2 \mathrm{M}$ hydrochloric acid and was filtered. Then, the filtrates were treated with Wagner's reagent (Iodine in Potassium Iodide). The formation of brown/reddish precipitate indicated the presence of alkaloids in the extracts.

- Screening for Anthraquinones: A $1 \mathrm{~mL}$ of each extracts was added with few drops of $10 \%$ ammonia solution. The formation of pink precipitate indicated the presence of anthraquinones.
- Screening for Coumarins: A $1 \mathrm{~mL}$ of each extracts was treated with $3 \mathrm{~mL}$ of $10 \% \mathrm{NaOH}$. The presence of coumarins was indicated by the formation of yellow color.

- Screening for Flavonoids (Alkaline Reagent Test): A $1 \mathrm{ml}$ of each extracts was treated with 5 drops of $1 \mathrm{M}$ sodium hydroxide solution. The formation of an intense yellow color indicated the presence of flavonoids.

- Screening for Saponins (Foam Test): A $0.5 \mathrm{~mL}$ each extracts was treated with $5 \mathrm{~mL}$ of distilled water. It was shaken vigorously for 15 minutes. The formation of foam that persists for about ten minutes indicated the presence of saponins.

- Screening for Tannins: A $1 \mathrm{~mL}$ of each extracts was treated with $2 \mathrm{~mL}$ of $5 \%$ ferric chloride solution. The formation of a dark blue or greenish black color indicates the presence of tannins.

- Screening for Terpenoids: A $0.5 \mathrm{~mL}$ of each extracts was treated with $2 \mathrm{~mL}$ of chloroform. The solution was carefully added with $1 \mathrm{~mL}$ of concentrated sulfuric acid. The formation of red brown color at the interface indicates the presence of terpenoids.

\subsection{Toxicity test: Brine shrimp lethality assay}

This procedure is as follows:

- Constant Weighing: Five milliliters of $A$. racemosa shell/seed extracts were added to the pre-weighed aluminum dish and dried in an oven to evaporate its solvent. The samples were put in a desiccator and weighed. The procedure was repeated until constant weight to determine its concentration.

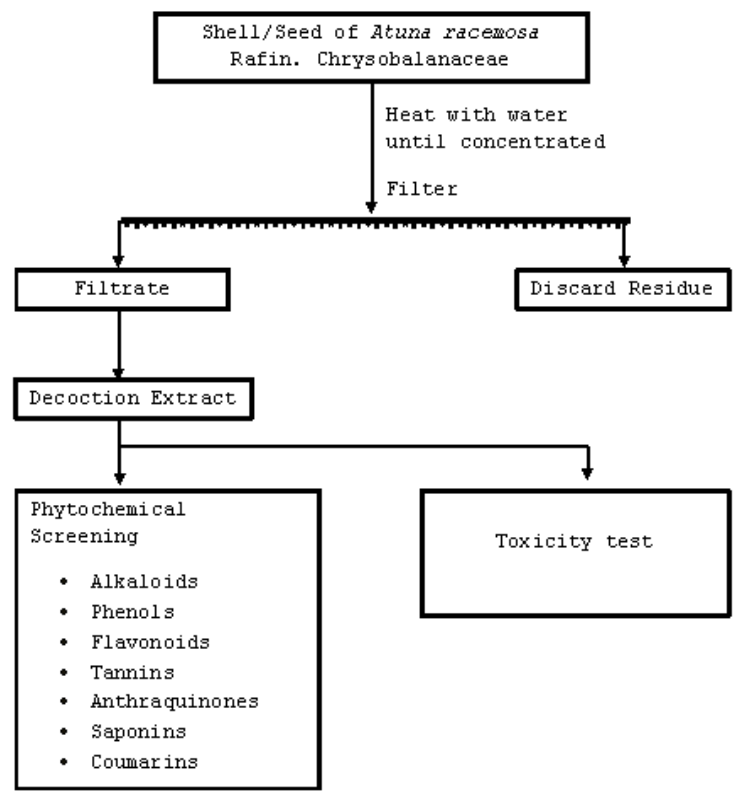

Fig. 2: Schematic diagram for the decoction extract of $A$. racemosa testing

- hrimp Hatching: Brine shrimp eggs were obtained from the New Aqua Laboratory in Naawan, Misamis Oriental, as a gift sample for the research work. Seawater was collected at Luz Banzon, Jasaan Misamis Oriental, and was filtered. One liter of 
seawater was used to fill a small plastic container and added with one gram of brine shrimp eggs. The controlled aerator was put inside the container. Two days were allowed for the shrimp to hatch and mature as nauplii (larva).

- Test Extracts: The concentrations of each extract calculated were used to calculate the required volume needed for stock solutions. The equation below shows how to calculate the volume of extract required for stock solutions (1)

$$
\text { Vol of extract }(m L)=\text { Css } x \text { Vss } / \text { Cext }
$$

where Css is the concentration of the stock solution (ppm); Vss is the volume of the stock solution (mL); and Cext is the concentration of the extract (ppm).

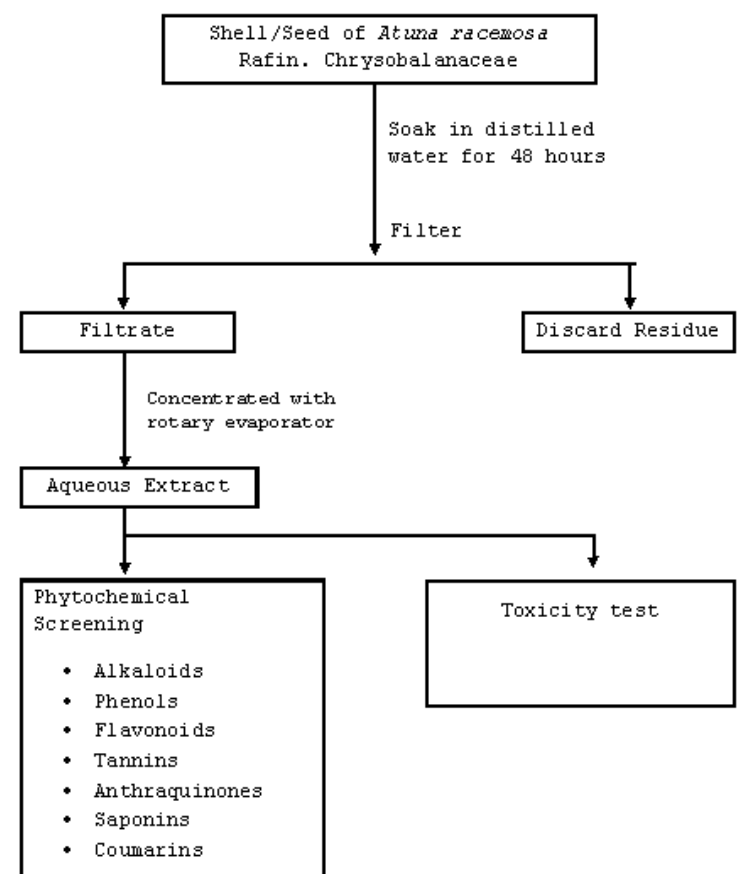

Fig. 3: Schematic diagram for the aqueous extract of $A$. racemosa testing

The volume of extract calculated for each concentration of stock solution (10000 ppm or 5000 ppm) was diluted to $5 \mathrm{~mL}$ of methanol. The final concentrations used were $1000 \mathrm{ppm}, 500 \mathrm{ppm}$, and $100 \mathrm{ppm}$. The test tubes for each prepared solution of the different concentrations were labeled and airdried until the solvent thoroughly evaporated. Five replicates were performed for each concentration level.

- Bioassay: Into each test tube containing the airdried extracts, $5 \mathrm{~mL}$ of seawater was added and stirred. A control sample was prepared consisting only of $5 \mathrm{~mL}$ of seawater. Ten brine shrimp nauplii were transferred into each test tube. Thus, there were a total of 50 brine shrimps per dilution. Using a magnifying glass or naked eye, the number of surviving shrimps were counted and recorded after 24 hours. The percent mortality (\%M) was calculated by dividing the number of dead nauplii by the total number, and then multiplied by $100 \%$.
This is to ensure that the death of the brine shrimp nauplii is attributed to the bioactive compounds present in plant extracts. Using probit analysis in minitab software, the lethality concentration $\left(\mathrm{LC}_{50}\right)$ was assessed at $95 \%$ confidence intervals. Toxicity profile of extracts was classified according to Clarkson's criteria for the toxicity assessment of plant extracts shown in Table 1.

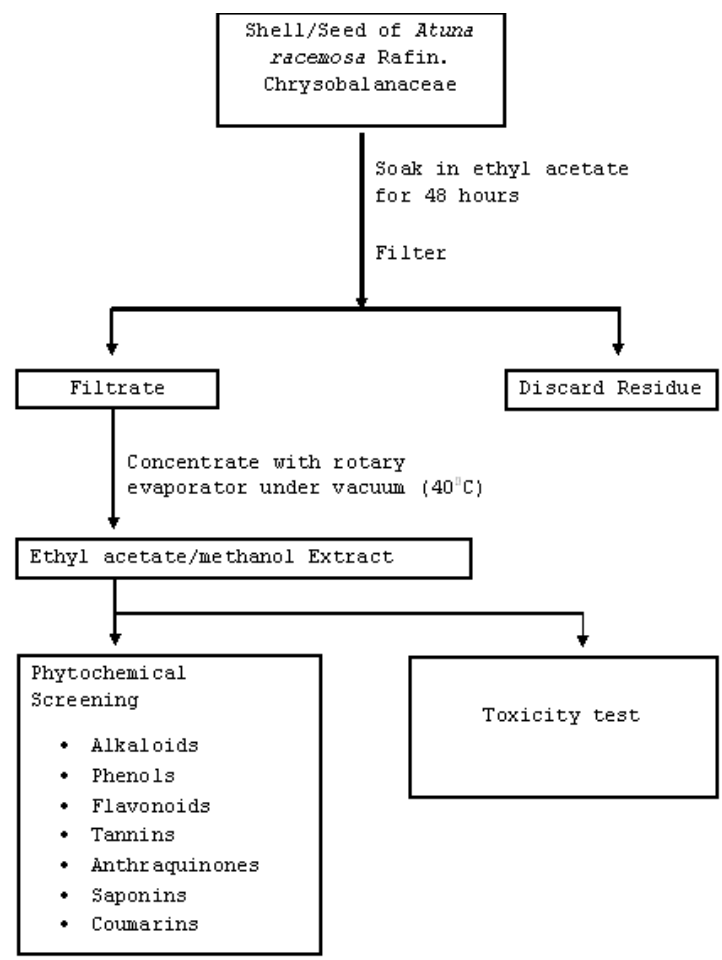

Fig. 4: Schematic diagram for the ethyl acetate and methanol extracts of $A$. racemosa testing

Table 1: Clarkson's Toxicity Assessment of Plant Extracts (Clarkson et al., 2004)

\begin{tabular}{cc}
\hline $\mathrm{LC}_{50}(\mu \mathrm{g} / \mathrm{mL})$ concentration & Toxicity Profile \\
$0-100$ & Highly Toxic \\
$100-500$ & Medium Toxic \\
$500-1000$ & Low Toxic \\
$1000-$ above & Non-toxic \\
\hline
\end{tabular}

\section{Results and discussion}

\subsection{Phytochemical screening}

The phytochemical characteristics of eight extracts tested were summarized in Table 2. The results revealed that the methanol extracts contain a greater number of different phytochemicals that were screened than the aqueous, ethyl acetate and decocted extracts. The extracts from $A$. racemosa shell and seed obtained different phytochemicals because of the different chemical characteristics and polarities present in the plant parts that were soluble to a particular solvent. Ethyl acetate is the least polar, then methanol and water as the most polar. Water is more polar than methanol but the higher activity of the methanolic extracts can be attributed to the presence of higher amounts of polyphenols as compared to other extracts (Tiwari et al., 2011). It means that they are more efficient in cell 
walls and seeds degradation which have unpolar character and cause polyphenols to be released from cells. An enzyme polyphenol oxidase degrades polyphenols in water extracts, whereas in methanol they are inactive. Since nearly all of the identified components from plant active against microorganisms are aromatic or saturated organic compounds, they are most often obtained through methanolic extraction (Tiwari et al., 2011).

Phytochemical analysis conducted on the shell and seed of $A$. racemosa extracts revealed the presence of secondary metabolites which are known to exhibit medicinal as well as physiological activities. From the table, it could be seen that saponins were present in all the $A$. racemosa shell and seed extracts. Saponins are rich in pharmaceutical properties such as the ability to increase immune responses and possession of antibacterial, antioxidant, anticancer, antidiabetic and anti-obesity properties (Abioye et al., 2013). It has the property of precipitating and coagulating red blood cells, forming foams in aqueous solutions, hemolytic activity, cholesterol binding properties and bitterness (Okwu, 2005).

Table 2: Phytochemical profile of the seed and shell extracts

\begin{tabular}{|c|c|c|c|c|c|c|c|c|}
\hline \multirow{3}{*}{ Phytochemicals } & \multicolumn{8}{|c|}{ racemosa extracts } \\
\hline & \multicolumn{2}{|c|}{ Distilled Water (aqueous) } & \multicolumn{2}{|c|}{ Ethyl Acetate } & \multicolumn{2}{|c|}{ Methanol } & \multicolumn{2}{|c|}{ Distilled Water(decoction) } \\
\hline & Seed & Shell & Seed & Shell & Seed & Shell & Seed & Shell \\
\hline Alkaloids & + & - & + & + & + & - & + & - \\
\hline Anthraquinones & - & - & - & - & + & - & + & - \\
\hline Coumarins & + & - & - & - & + & - & - & - \\
\hline Flavonoids & - & - & + & + & + & + & - & - \\
\hline Saponins & + & + & + & + & + & + & + & + \\
\hline Tannins & + & + & - & - & + & + & + & + \\
\hline Terpenoids & + & + & - & - & + & + & + & + \\
\hline
\end{tabular}

Ethyl acetate extracts of $A$. racemosa shell and seed contain alkaloids, flavonoids and saponins. Alkaloids have been reported to exert analgesic, antispasmodic and antibacterial activities (Amirkia and Heinrich, 2014). Flavonoids also possess diverse biological activities, for instance, antiulcer, antiinflammatory, antioxidant, cytotoxic and antitumor, antispasmodic, antidepressant, and antimicrobial activities (Ghasemzadeh and Ghasemzadeh, 2011).

Aqueous and decocted extracts of $A$. racemosa shell contain the same phytochemicals which are saponins, tannins, and terpenoids. Tannins bind to proline rich protein, interfere with protein synthesis, and have antioxidant effects (Okuda and Ito, 2011). Tannins and terpenoids have both exhibit antimicrobial and antidiarrheal activities (Zwenger, 2008).

Aqueous and decocted seed extracts contain alkaloids, saponins, tannins and terpenoids except that coumarins are present in aqueous extract and anthraquinones are detected in decocted extract. Coumarins found to have bacteriostatic, anti-tumor, anticoagulant, and anti-inflammatory activities (Jain and Joshi, 2012). Plant extracts containing anthraquinones are increasingly used for cosmetics, food, dye and pharmaceuticals due to their wide therapeutic and pharmacological properties such as antioxidant, antifungal, antiviral and antimicrobial (Dave and Ledwani, 2012).

Methanol extracts of the seed contain all the phytochemicals tested, alkaloids, anthraquinones, coumarins, flavonoids, saponins, tannins, and terpenoids. While the methanol shell extracts contain flavonoids, saponins, tannins and terpenoids.

\subsection{Toxicity test: Brine shrimp lethality assay}

The brine shrimp lethality assay represents a rapid, inexpensive and simple bioassay for testing plant extracts bioactivity which in most cases correlates reasonably well with cytotoxic and antitumor properties (Krishnaraju et al., 2005). Brine shrimp lethality assay of $A$. racemosa shell and seed extracts are shown in Table 3 and Table 4. Percent mortality was obtained from 5 replicates of each concentration and used to determine the $50 \%$ lethal concentration. The $\mathrm{LC}_{50}$ at $95 \%$ confidence interval was calculated using probit analysis in minitab software.

The percent mortality (\%M) was calculated to ensure that the death of the brine shrimp nauplii is attributed to the bioactive compounds present in plant extracts. The degree of lethality was directly proportional to the concentration of the extract. As the concentration of tabon-tabon shell and seed extracts increases, the percent mortality also increases. In the Table 3 , maximum mortalities $(100 \%)$ were observed at a concentration of 1000 ppm in both ethyl acetate and methanol extract. While in Table 4, 100\% mortality was observed at 500 and 1000 ppm of methanol and decocted extracts, and $1000 \mathrm{ppm}$ in aqueous extracts.

According to Clarkson's toxicity criterion for the toxicity assessment of plant extracts, most of the $A$. racemosa extracts were medium toxic against brine shrimp nauplii except the highly toxic methanol seed.

The result shows that all of the tabon-tabon shell and seed extracts tested are considered active or toxic where $\mathrm{LC}_{50}$ values are less than $1000 \mu \mathrm{g} / \mathrm{mL}$ (Olowa and Nuñeza, 2013). Methanol extract of tabon-tabon seed was the most toxic extract in this study with a highly toxic $\mathrm{LC}_{50}$ of $92.0427 \mu \mathrm{g} / \mathrm{mL}$. Thus, it means that approximately $50 \%$ of the brine shrimp nauplii will not survive when exposed to a concentration of methanolic extract of $A$. racemosa seed at $92.0427 \mu \mathrm{g} / \mathrm{mL}$. While Methanol shell extract ranks as the second potent or active extract against 
brine shrimps at $116.032 \mu \mathrm{g} / \mathrm{mL} \mathrm{LC}_{50}$. The toxicity of methanol shell and seed extracts may be due to the observed phytochemicals present as shown in Table 2 , the extracts with the most number of phytochemicals tested. A positive correlation in the toxicity of methanol extract is observed with its antibacterial potential. A similar result from the study of Buenz et al. (2007) which suggest that there is likely more than one active compound in the methanol extract of tabon-tabon seed: certainly an antibiotic, however, also a compound effective at killing brine shrimp nauplii. However, the active components remain unidentified.

In $A$. racemosa shell, decocted extract shows medium toxicity against brine shrimp with the highest $\mathrm{LC}_{50}$ of $482.78 \mu \mathrm{g} / \mathrm{mL}$. While in the $A$. racemosa seed, ethyl acetate extract shows a medium toxic effect against nauplii having the highest $\mathrm{LC}_{50}$ value of all seed extracts of 419.919 $\mu \mathrm{g} / \mathrm{mL}$. According to its phytochemical profile, ethyl acetate extracts had the least presence of phytochemicals tested but showed the highest antibacterial activity against a gram negative bacteria. According to McLaughlin et al. (1998) pharmacology is simply toxicity at a lower dose which indicates that these findings about ethyl acetate extracts have implications for the use of this natural product as an antibiotic agent.
A. racemosa is toxic to brine shrimp nauplii which may also be toxic to humans. Hence, the use of tabon-tabon as spices for kinilaw and as folk medicine in treating ulcer should be minimized in concentration as it may cause negative effects to humans at high dosages.

\section{Conclusion}

Overall, phytochemical screening of $A$. racemosa seed methanolic extract revealed the presence of all phytochemicals tested, alkaloids, anthraquinones, coumarins, flavonoids, saponins, tannins, and terpenoids. The $A$. racemosa shell methanolic extract contains flavonoids, saponins, tannins and terpenoids only. For ethyl acetate extracts, both $A$. racemosa shell and seed contain alkaloids, flavonoids and saponins.

For aqueous extract, the $A$. racemosa seed shows the presence of alkaloids, coumarins, saponins, tannins and terpenoids while $A$. racemosa shell has saponins, tannins and terpenoids only. For decoction extracts, A. racemosa seed has the presence of alkaloids, anthraquinones, saponins, tannins and terpenoids while $A$. racemosa shell contains saponins, tannins and terpenoids only.

Table 3: Toxicity of A. racemosa Shell Extracts with Varying Concentrations on Artemia salina

\begin{tabular}{|c|c|c|c|c|}
\hline Concen-tration & \% Mortality & $\mathrm{LC}_{50}(\mu \mathrm{g} / \mathrm{mL})$ & $95 \%$ Confidence Interval & Toxicity Profile \\
\hline \multicolumn{5}{|c|}{ Aqueous extract } \\
\hline 100 & 42 & & & \multirow{3}{*}{ Medium Toxic } \\
\hline 500 & 48 & 268.605 & $44.7643-637.082$ & \\
\hline 1000 & 70 & & & \\
\hline \multicolumn{5}{|c|}{ Ethyl acetate extract } \\
\hline 100 & 15.3 & & & \\
\hline 500 & 62 & 277.9 & $220.404-345.060$ & Medium Toxic \\
\hline 1000 & 100 & & & \\
\hline \multicolumn{5}{|c|}{ Methanol extract } \\
\hline 100 & 48 & & & \\
\hline 500 & 80 & 116.032 & $68.0558-163.502$ & Medium Toxic \\
\hline 1000 & 100 & & & \\
\hline \multicolumn{5}{|c|}{ Decoction extract } \\
\hline 100 & 32 & & & \\
\hline 500 & 44 & 482.78 & $244.208-1356.57$ & Medium Toxic \\
\hline 1000 & 64 & & & \\
\hline
\end{tabular}

Table 4: Toxicity of A. racemosa Seed Extracts with Varying Concentrations on Artemia salina

\begin{tabular}{|c|c|c|c|c|}
\hline Concen-tration & \% Mortality & $\mathrm{LC}_{50}(\mu \mathrm{g} / \mathrm{mL})$ & 95\% Confidence Interval & Toxicity Profile \\
\hline \multicolumn{5}{|c|}{ Aqueous extract } \\
\hline 100 & 32 & & & \multirow{3}{*}{ Medium Toxic } \\
\hline 500 & 82 & 165.195 & $120.843-212.713$ & \\
\hline 1000 & 100 & & & \\
\hline \multicolumn{5}{|c|}{ Ethyl acetate extract } \\
\hline 100 & 19.61 & & & \\
\hline 500 & 49.02 & 419.919 & $295.155-606.467$ & Medium Toxic \\
\hline 1000 & 74.51 & & & \\
\hline \multicolumn{5}{|c|}{ Methanol extract } \\
\hline 100 & 62 & & & \\
\hline 500 & 100 & 92.043 & Significant at $0.05 \%$ & Medium Toxic \\
\hline 1000 & 100 & & & \\
\hline \multicolumn{5}{|c|}{ Decoction extract } \\
\hline 100 & 20 & & & \\
\hline 500 & 100 & 121.111 & Significant at $0.05 \%$ & Medium Toxic \\
\hline 1000 & 100 & & & \\
\hline
\end{tabular}

All of the extracts showed positive towards toxicity testing, indicating that the test samples are biologically active. Approximately $50 \%$ of the brine shrimp nauplii will not survive when exposed to aqueous extracts of $A$. racemosa shell and seed at a concentration of $268.605 \mu \mathrm{g} / \mathrm{mL}$ and $165.195 \mu \mathrm{g} / \mathrm{mL}$ 
respectively. For ethyl acetate extracts, the $A$. racemosa shell and seed showed a 50\% lethal concentration at $267.209 \mu \mathrm{g} / \mathrm{mL}$ and 419.919 $\mu \mathrm{g} / \mathrm{mL}$, respectively. The methanol extracts of $A$. racemosa shell and seed are potent against brine shrimps nauplii with $\mathrm{LC}_{50}$ values of $116.032 \mu \mathrm{g} / \mathrm{mL}$ and $92.0427 \mu \mathrm{g} / \mathrm{mL}$. And for decoction extracts, approximately $50 \%$ of nauplii will not survive at $A$. racemosa shell and seed concentrations of 482.78 $\mu \mathrm{g} / \mathrm{mL}$ and $121.111 \mu \mathrm{g} / \mathrm{mL}$, respectively. According to Clarkson's criterion, methanol seed extract was highly toxic towards brine shrimp nauplii while the other $A$. racemosa shell and seed extracts were medium toxic towards brine shrimp nauplii.

\section{References}

Abioye EO, Akinpelu DA, Aiyegoro OA, Adegboye MF, Oni MO, and Okoh AI (2013). Preliminary phytochemical screening and antibacterial properties of crude stem bark extracts and fractions of Parkia biglobosa (Jacq.). Molecules, 18(7): 8485 8499.

Amirkia V and Heinrich M (2014). Alkaloids as drug leads-A predictive structural and biodiversity-based analysis. Phytochemistry Letters, 10: xlviii-liii. https://doi.org/ 10.1016/j.phytol.2014.06.015

Buenz EJ (2006). A brief communication Hepatocytes Detoxify Atuna racemosa extract. Experimental Biology and Medicine, 231(11): 1739-1743.

Buenz EJ (2007). Mitochondrial involvement in Atuna racemosa induced toxicity. Journal of Ethno Pharmacology, 109(2): 304311.

Buenz EJ, Tillner JE, Limburg P, and Bauer BA (2007). Antibacterial properties and toxicity of Atuna racemosa extract depend on kernel maturity. Journal of Ethno Pharmacology, 111(3): 592-597.

Clarkson C, Maharaj VJ, Crouch NR, Grace OM, Pillay P, Matsabisa MG, and Folb PI (2004). In vitro antiplasmodial activity of medicinal plants native to or naturalised in South Africa. Journal of Ethno Pharmacology, 92(2): 177-191.

Dave $\mathrm{H}$ and Ledwani L (2012). A review on anthraquinones isolated from Cassia species and their applications. Indian Journal of Natural Products and Resources, 3(3): 291-319.

Dhalwal K, Deshpande YS, and Purohit AP (2007). Evaluation of in vitro antioxidant activity of Sida rhombifolia (L.) ssp. retusa (L.). Journal of Medicinal Food, 10(4): 683-688.

Ghasemzadeh A and Ghasemzadeh N (2011). Flavonoids and phenolic acids: Role and biochemical activity in plants and human. Journal of Medicinal Plants Research, 5(31): 66976703.

Jain PK and Joshi H (2012). Coumarin: Chemical and pharmacological profile. Journal of Applied Pharmaceutical Science 2(6): 236-240.

Krishnaraju AV, Rao TV, Sundararaju D, Vanisree M, Tsay HS, and Subbaraju GV (2005). Assessment of bioactivity of Indian medicinal plants using brine shrimp (Artemia salina) lethality assay. International Journal of Applied Science and Engineering, 3(2): 125-134.

Mclaughlin JL, Rogers LL, and Anderson JE (1998). The use of biological assays to evaluate botanicals. Drug information journal, 32(2): 513-524.

Okuda $\mathrm{T}$ and Ito $\mathrm{H}$ (2011). Tannins of constant structure in medicinal and food plants-hydrolyzable tannins and polyphenols related to tannins. Molecules, 16(3): 2191-2217.

Okwu DE (2005). Phytochemicals, vitamins and mineral contents of two Nigerian medicinal plants. International Journal of Molecular Medicine and Advance Sciences, 1(4): 375-381.

Olowa LF and Nuñeza OM (2013). Brine shrimp lethality assay of the ethanolic extracts of three selected species of medicinal plants from Iligan City, Philippines. International Research Journal of Biological Sciences, 2(11): 74-77.

Tiwari P, Kumar B, Kaur M, Kaur G, and Kaur H (2011). Phytochemical screening and extraction: A review. Internationale Pharmaceutica Sciencia, 1(1): 98-106.

Zwenger S (2008). Plant terpenoids: Applications and future potentials. Biotechnology and Molecular Biology Reviews, 3(1): 1-7. 